\title{
Green Computing: Optimize Design of Solar Based Power Supply Unit for IOT
}

\author{
Sajida Parveen ${ }^{1}$, Kamran Ali', Nadeem Naeem 1 , Intesab Hussain Sadhayo' and Farhana Umer ${ }^{2}$ \\ 'Quaid-e-Awam University of Engineering Science and Technology Nawabshah, Shaheed Benazirabad, \\ Sindh 67450,Pakistan; 11it@quest.edu.pk,nadeembhatti@quest.edu.pk, intesab@quest.edu.pk, \\ 2Department of Electrical Engineering, Islamia University Bahawalpur, Bahawalpur, \\ Pakistan; farhana.umer@iub.edu.pk
}

\begin{abstract}
Objectives: To design a solar based power supply unit that can replace normal power supply in Internet of Things (IoT) devices specifically computers without compromising the efficiency of the devices. It also helps to minimize the ratio of $\mathrm{Co}_{2}$ emission of digital devices which is a big threat now days for environment. Statistical Analysis: Basically, a circuit of DC power supply unit is design for desktop computers. These computers can work on 12 volts DC power supply in green computing environment. Moreover, 5 and 3 volts are generated for initial power and internal components of the computer. Moreover, the statistical analysis is carried out on the bases of energy consumption of the user in Pakistan. Findings: The solar power can save our energy cost up to 208 volts because normal power supply works on 220 volts and new designed power supply can work on 12 volts which are too less than 220 . This research work provides a potential technique for green IoT environment. Application: the proposed DC power supply unit will be very helpful to run the IoT components directly on solar systems. Moreover, because of minimum power consumption of IoT it also reduces the carbon emissions that would be good for environment.
\end{abstract}

Keywords: DC Power Supply Unit, Energy Consumption, Green Computing, Internet of Things (IoT), Solar Based Power Supply

\section{Introduction}

The internet globally connects the world as a small town. There are various devices of Internet of Things (IoT) which help to connect things to each other such as sensors, RFID, cars, computer, mobile devices and home appliances. Therefore, IoT is everything around us which should be communicated "anytime, anywhere, any media and anything". Beside various advantages of IoT in broad rang applications such as healthcare, transport, industry, home and education systems as shown in Figure 1 but it also consume high power and big energy. The IoT utilized numerous devices for their functionality but it also demands big energy for its various functions. However this energy demand and e-waste produce stress in our environment. To overcome the issues of this IoT in the smart world development, recently the green IoT is introduced to minimize the carbon emission and power con- sumption ${ }^{1}$. Due to increasing demand of IoT, the amount of electricity consumed by IoT devices is also goes up. Green computing or greening IoT electronic devices comes with energy star label, which means the devices are approved from Environmental Protection Agency (EPA) to consume low power on the basis of ratings. Nowadays, companies are focusing for power and energy saving techniques and infrastructure. They also believe in using green devices for better environment and give preference at it higher level ${ }^{2}$. Because of eco friendly properties, most of the IoT vendors are investing in the development of energy efficient devices which lead them to beat the market via increase in demand so as a cost. It ultimately reduces the usage of material which is dangerous and also encouraging the reusability of digital devices. Therefore, recent research is proving the latest trends and models for utilizing the green computing and also promoting the vendors investments ${ }^{3}$. 


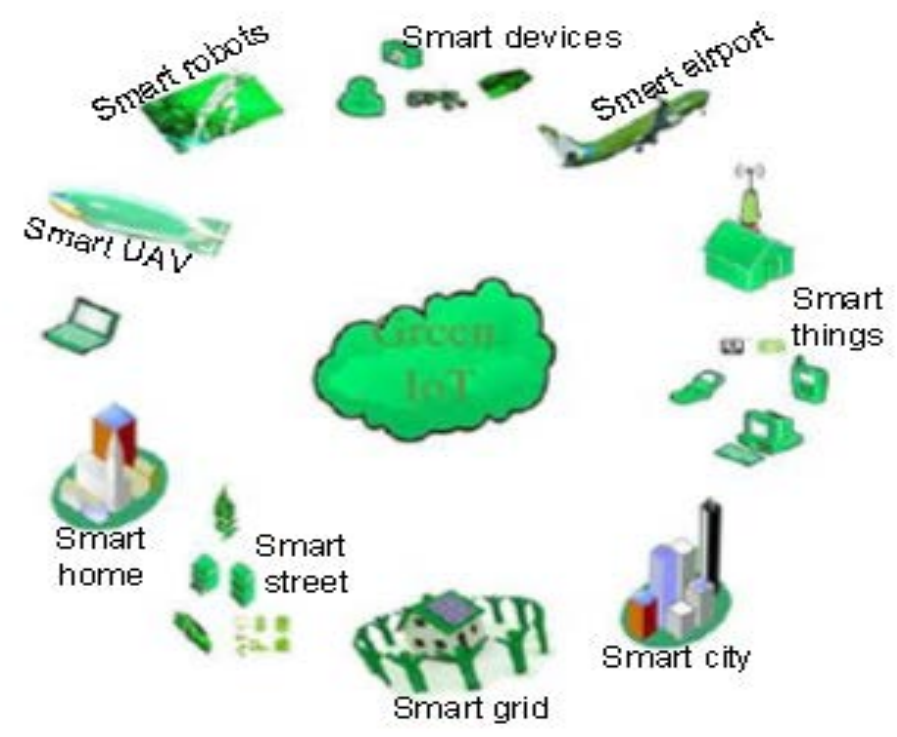

Figure 1. Green computing.

These green computing methodologies provide a protection and improve the living standard for modern world. Green computing is the study and practice of designing, manufacturing, using and disposing of computers, servers and associated subsystems: such as monitors, printers, storage devices, and networking and communication systems efficiently and effectively with minimal or no impact on the environment. It was primarily addressed by enhanced research and development efforts to reduce power usage, heat transmission, cooling needs of hardware devices, in particular processor chips using extensive hardware controls ${ }^{4}$.

Nowadays, companies and common users are dealing much financial pressure regarding electricity bills and paying attention to recover from this issue. Therefore, they started to switch on green computing technologies and make their home and workplace ecofriendly. Currently, world are paying much more attention and give a high priority to save energy without compromising efficiency and protect the environment from e-toxics. Various organizations regardless of their sizes are converting the systems on IoT models and implement green computing environment for resolving the recent electricity's issues and utilizing lower energy with highest performances. Ultimately the usage of energy and its associated cost plays important part for green computing growth in national and global level. Due to higher consumption of energy in data centers and usage of desktop computers in industries, green computing place immediate impact on business value and remain focused for its implementation $^{5}$.

New trends of green computing focus on IoT and investigate latest computing models and applications with lower cost and power consumption and promote the sustainable development and economy and society ${ }^{6}$. The main purpose of green computing is highly correlated with the consumption of energy in computational devices and supporting electronics along with secondary energy consumers such as climate control during deployment. However, before considering the problem of sustainable or green computing it is very important to take an account of other environmental concerns such as impact of material and energy on electronic device manufacturing. Similarly, after complete utilization and completion of services the recycling and disposal of these devices also leave big impact on environment. Thus, it is necessary to consider throughout the impact of life-cycle of devices (i.e. manufacturing to disposal) on entire environment via deployments of $\mathrm{IoT}^{7}$. It can be seen from the above discussion that continuous advancement in technology is the key to improve the performance on given power consumption level. For example, CPUs, data storage and servers can perform and achieved higher efficiency level as compare to the pervious one on minimum energy consumptions levels ${ }^{8}$. Normally, desktop computers have internal power supplies which convert the AC power supply i.e. $120 \mathrm{~V}$ to $\mathrm{DC}$ voltages for the other subcomponent of the computers such as microprocessor and associated 
components. These DC voltages converted to the appropriate levels required for subcomponents. Other principle components such as monitor, printer or plotter works on directly on AC power lines which are provided either directly from the main line or from a feed-through path which is allocated in the back of computer as a plug. At the time of running programs and data on the personal computer may loss during computing environment of $\mathrm{AC}$ power loss. Moreover, due to the fluctuation of AC power lines resultant in damage of various main components like disk drives etc. Even slight glitch in AC power can cause of a data loss which can lead to incorrect results.

Prior work provides the solutions for this AC power supply loss and one of them is uninterruptible power supplies that provide alternative power to computers. However, these solutions are not enough in terms of efficiency neither integrated in the circuits. Furthermore, an invention came up with idea that an integrated uninterruptable power supply which provide both AC and DC for personal computer ${ }^{9}$. An another approach has been proposed in which emergency power supply unit is designed which firstly detect the AC power failure and then in second phase SC transformer with a high step-up transformer is utilized to supplies power of commercial level high voltages ${ }^{10}$. From the literature it is clear that the power and energy supposed to be a key part of the solutions when considering the design aspects across a range of super computer to data center computing. Study shows that industries and organizations are given importance to energy efficient methods for desire work.

Meanwhile pervious work can be summarized into simple works i.e. "Avoid waste". The recent research is conducting to finding on the source and reasons of wastage and figuring out to minimize this form environment. The energy awareness system strategies are totally based on green computing in IoT. This strategy does not affect directly the current applications but it also control the power consumptions aspects regarding underlying hardware utilization. Basically, IoT makes the working place and home smarter (automatic) system to turn off, on and other control management ${ }^{11}$. The major reason behind the growth of internet is the popularity of IoT in our societies. Meanwhile, IoT and other industrial computers also leave some impact on environment. According to the statistics, total amount of global data center power consumptions is about $2 \%$ of total carbon-di-oxide emission. IoT and other computer based systems and equipment produced 35 million tons of exhaust which is equivalent to carbon emission in any industry ${ }^{12,13}$. Green IoT growing since few years back because of constant pressure on IoT energy usage. Green IoT consists on green products and eco-friendly equipment to reduce carbon emission and enhance the energy efficiency.

\section{Proposed Design}

In most of the third world country, there is the problem of shortage of electricity and fluctuations in the voltages which damages most of the electronics devices. In this study the idea is proposed to work on 12 volts instead on 220 volts. In order to achieve this idea, a circuit is designed of a 12 volts DC Power Supply Unit (PSU) for many IoT devices which will work on batteries / solar system without lowering the performance of the system. The Figure 2
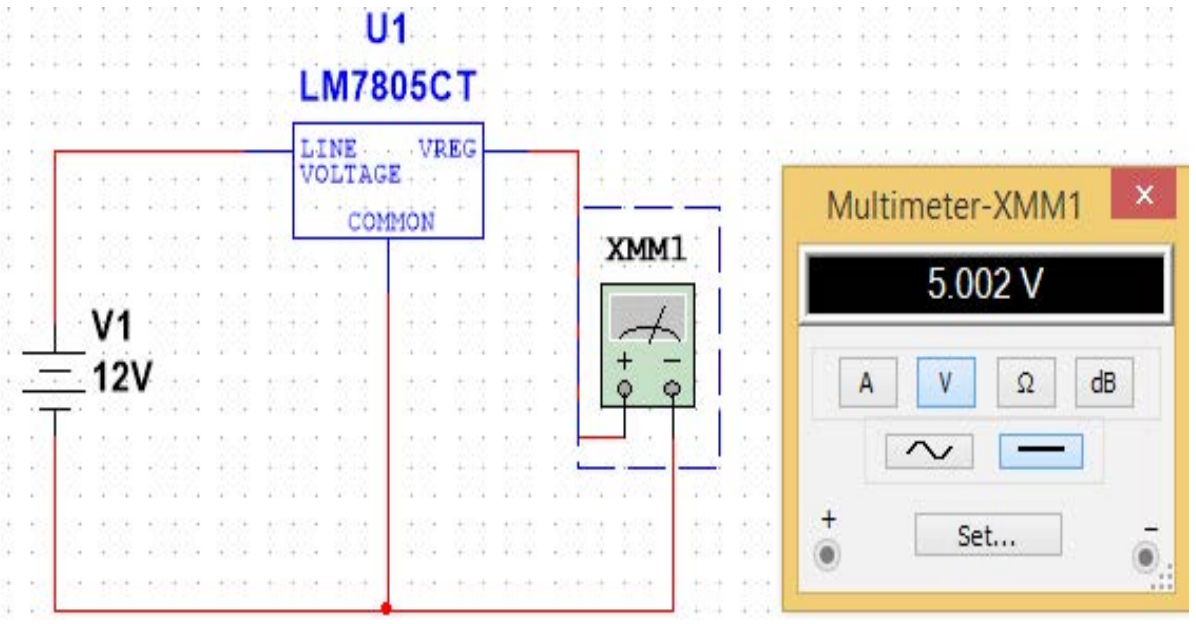

Figure 2. Circuit diagram with conversion of 12 volts to 5 volts. 
depicts the conversion of $12 \mathrm{~V}$ power supply into5V for ease of electronic circuit sub components. Normally, plus or minus five percent range from the nominal intended setting is acceptable.

\section{Discussion and Comparative Analysis on Energy Consumption}

From the literature it is clear that computer and laptop consumptions leave impact on environment via releases toxic chemicals and carbon dioxide with the usage of huge electricity. An estimated statistics regarding the energy consumptions and $\mathrm{CO}_{2}$ emission in Pakistan for desktop and laptop is given in Table 1.Through the statistics of Pakistan it is calculated that up to $27 \%$ of total 170 million populations consumed the overall energy in different industries and home computers. Approximately, among this $27 \%$ user, $20 \%$ are desktop and $7 \%$ are laptop users. The energy consumption on daily and yearly basis data is calculated and determined in Whr. In Table 1 and Figure 3, huge energy consumption is shown via calculated data i.e. 47.6 GW/hr daily and $17374 \mathrm{GWhr}$ on yearly basis with a toxic release of 12161 million ton of $\mathrm{C}_{2}$ yearly. This hazard spills environment about and identifying an alarming situation for Pakistan. Several survey projects have been done on this issue and suggested a green computing system for real time PV applications. From the data it can see that although energy consumption for laptop is less than desktop, but still yearly massive electricity consumption takes place. Thus there is a need of a solution or system that reduces carbon emission in computer based industries.

In order to overcome this environmental threat, a novel energy efficient DC power supply is proposed in this study. The same statistics as discussed in Table 1 applied on newly designed circuit and calculates some

Table 1. Energy consumption of desktop

\begin{tabular}{|l|l|l|l|}
\hline Sl. No. & Parameter & Traditional & Proposed design \\
\hline 1. & Users Approx. & 34 Millions & $34 \mathrm{Millions}$ \\
\hline 2. & Average energy consumption & $175 \mathrm{~W} / \mathrm{hr}$ in $1 \mathrm{hour}$ & $85 \mathrm{~W} / \mathrm{hr}$ in $1 \mathrm{hour}$ \\
\hline 3. & Daily energy consumption & $175 \mathrm{~W} / \mathrm{hr} r^{\star} \mathrm{hr}=1400 \mathrm{~W} / \mathrm{hr}$ & $85 \mathrm{~W} / \mathrm{hr} \mathrm{hr}^{\star} \mathrm{hr} 680 \mathrm{~W} / \mathrm{hr}$ \\
\hline 4. & Users daily consumption & $34 \mathrm{M}^{\star} 1400 \mathrm{~W} / \mathrm{hr}=47.6 \mathrm{GW} / \mathrm{hr}$ & $34 \mathrm{M}^{\star} 680 \mathrm{~W} / \mathrm{hr}=23.120 \mathrm{GW} / \mathrm{hr}$ \\
\hline 5. & Yearly consumption & $47.6 \mathrm{GW} / \mathrm{hr}^{\star} 365=17374 \mathrm{GW} / \mathrm{hr}$ & $23.12 \mathrm{GW} / \mathrm{hr}^{\star} 365=8438 \mathrm{GW} / \mathrm{hr}$ \\
\hline
\end{tabular}

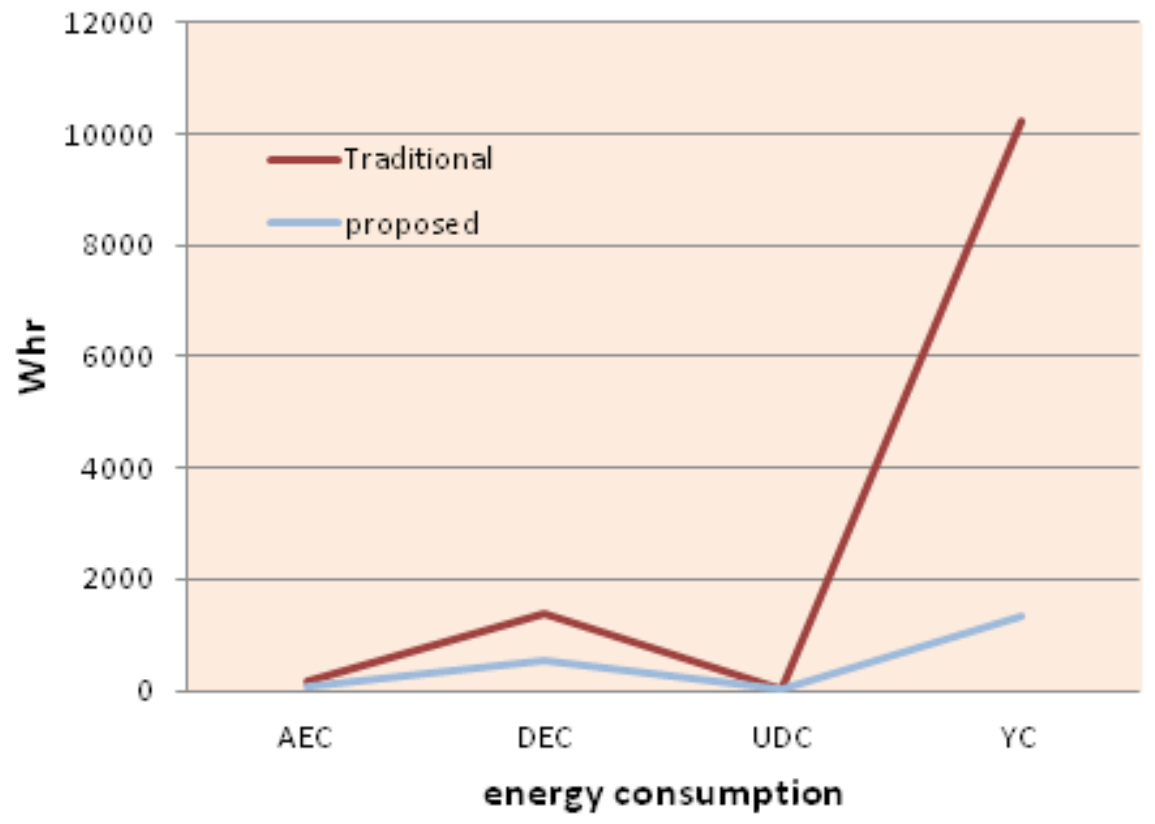

Figure 3. Comparative analysis of energy consumption. 
experimental data on power consumption and carbon emission. By utilizing 12 volts DC Power Supply Unit (PSU) an experiment is conducted on desktop computer as considering an example. The digital electronic components and circuits in the desktop computer system such as motherboard, adapter cards, and disk drive logic boards typically uses the $+3.3 \mathrm{~V}$ or $+5 \mathrm{~V}$ power and the motors like disk drive motors and any fan uses the $+12 \mathrm{~V}$ power. To provide such amount of voltages to particular component, there are voltage regulators on the motherboard or in other components which convert these standard voltages to others as necessary requirements or according to the component consumption. In Figure 2, the circuit shows the voltage conversion from 12 volts to 5 volts and Figure 4 shows the voltage conversion from 12 volts to 3.3 volts which could be the required amount of voltage needs to run a subcomponents.

The statues of energy consumption and carbon emissions by desktop computer users by utilization of proposed solar based DC power supply unit is calculated in Table 2. The marginal reduction i.e. $720 \mathrm{Whr}$ in energy consumption of daily basis and 8936GWhr on yearly basis of desktop computer is shown from the Figure 3. Similarly, in Figure 5 the carbon emission is reduced up to $50 \%$. Thus estimated results from the proposed novel DC power supply circuit shows a marginal result and could be very useful for industries without compromising on efficiency and can contribute in green computing.
Table 2. Co2 Emission in 1 year in Pakistan

\begin{tabular}{|l|l|l|}
\hline Parameter & Traditional & Proposed Design \\
\hline $\begin{array}{l}\mathrm{CO}_{2} \text { annual } \\
\text { emission }\end{array}$ & $\begin{array}{l}0.7^{\star} 17374=12161 \\
\text { Million ton }\end{array}$ & $0.7^{\star} 8438=5906.6$ \\
\hline
\end{tabular}

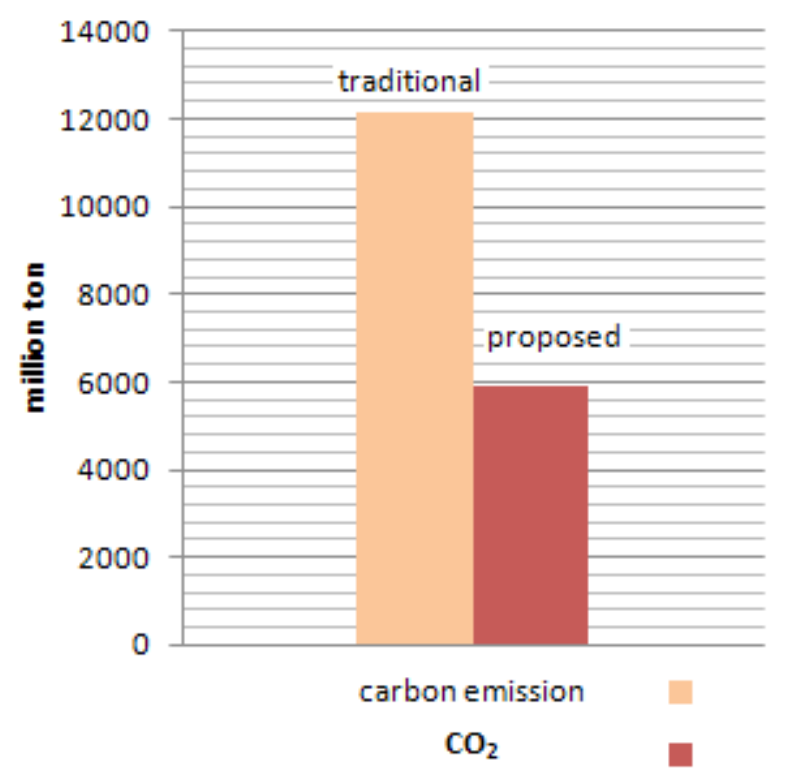

Figure 5. Comparison of carbon emission of traditional $v s$ proposed power supply.

\section{Conclusions}

The tremendous development in IoT brings many advantages. However, this growth of IoT demands for

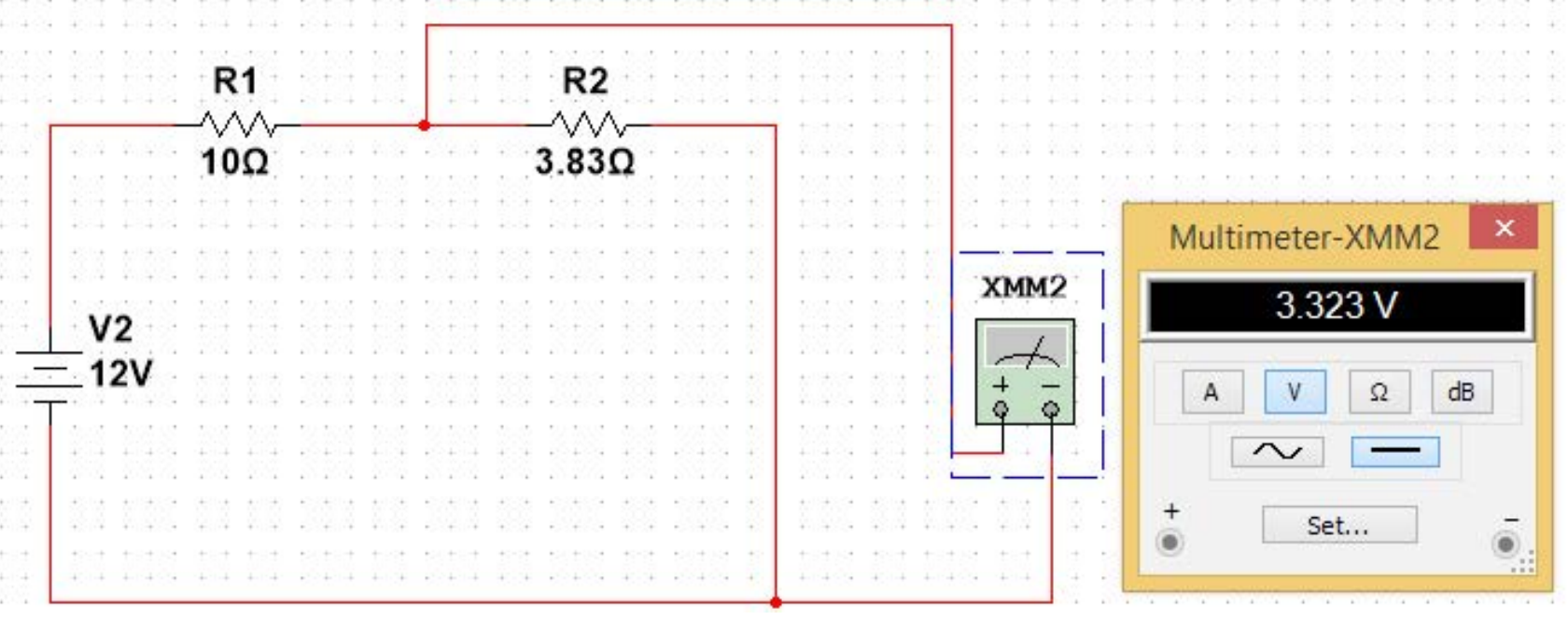

Figure 4. Circuit diagram with conversion of 12 volts to 3.3 volts. 
high energy consumption with hazardous emission and e-waste. In this study, the idea of solar based DC power supply is introduced in order to solve the problem of shortage of electricity and fluctuations in the voltages in under developing country and a huge threat of $\mathrm{Co}_{2} \mathrm{e}$ for environment. These problems may increase the damages most of the electronics devices of IoT as well as contribute to global energy. Firstly, the main purpose of introducing solar DC power supply unit is that IoT devices can not directly connected to solar system because they need a internal power supply unit that should work on $12 \mathrm{~V}$ and can supply the desired voltages to subunit of the system. Secondly, this new DC power supply unit will be very helpful to run the IoT components directly on solar systems. Moreover, because of minimum power consumption of IoT it also reduces the carbon emissions.

\section{References}

1. Greening Internet of Things for Smart Every things with a Green-Environment Life: A Survey and Future Prospects. Date accessed: 02/05/2018. https://arxiv.org/ abs/1805.00844.

2. Green Computing and Internet of Things. Date accessed: 18/08/2018. http://gciot-conference.org/2018/iot17.html.

3. Maksimovic $M$. The role of Green Internet of Things (G-IoT) and big data in making cities smarter, safer and more sustainable, International Journal of Computing and Digital Systems. 2017; 6(4):2210-142. https://doi. org/10.12785/IJCDS/060403.

4. Singh S. Green computing strategies and challenges. In: Green Computing and Internet of Things (ICGC IoT). IEEE International Conference; 2015. p. 758-60. https:// doi.org/10.1109/ICGCIoT.2015.7380564.
5. Harmon RR, Auseklis N. Sustainable IT Services: Assessing the Impact of Green Computing Practices. In: Management of Engineering and Technology. IEEE Portland International Conference; 2009. p. 1707-17.

6. Li Q, Zhou M. The survey and future evolution of green computing. In: Proceedings of the 2011 IEEE/ACM International Conference on Green Computing and Communications; 2011. p. 230-33. https://doi.org/10.1109/ GreenCom.2011.47.

7. Jones AK, Liao L, Collinge WO, Xu H, Schaefer LA, Landis AE, Bilec MM. Green computing: A life cycle perspective. IEEE International Green Computing Conference (IGCC); 2013. p. 1-6. https://doi.org/10.1109/IGCC.2013.6604497.

8. Wang D. Meeting Green Computing Challenges. In: Electronics Packaging Technology Conference; 2008. p. 121-26. https://doi.org/10.1109/EPTC.2008.4763421.

9. Integrated Uninterruptible Power Supply for Personal Computers. Date accessed: 1989. https://patents.google. com/patent/US4860185.

10. Ueno F, Inoue T, Oota I, Harada I. Emergency Power Supply For Small Computer Systems. In: Circuits and Systems. IEEE International Sympoisum on Circuits and Systems; 1991 2. p. $1065-68$.

11. Krithika B, Keerthana N. Comparison of Intel Processor with AMD Processor with Green Computing. In: Green Computing, Communication and Conservation of Energy (ICGCE); 2013. p. 737-42. https://doi.org/10.1109/ ICGCE.2013.6823531.

12. Mao Y, You C, Zhang J, Huang, K, Letaief KB. A survey on mobile edge computing: The communication perspective, IEEE Communications Surveys and Tutorials. 2017; 19(4):2322-58. https://doi.org/10.1109/COMST.2017.2745201.

13. Wu Q, Li GY, Chen W, NgDWK, Schober R. An overview of sustainable green $5 \mathrm{G}$ networks, IEEE Wireless Communications. 2017; 24(4):72-80. https://doi.org/10.1109/ MWC.2017.1600343. 